\title{
An Assessment of NFC for Future Mobile Payment Systems
}

\author{
Jan Ondrus, Yves Pigneur \\ Department of Information Systems \\ University of Lausanne, Switzerland \\ \{jan.ondrus, yves.pigneur\}@unil.ch
}

\begin{abstract}
In this paper, we present an assessment of NFC (Near Field Communication) for future mobile payment systems. NFC is expected to become a very trendy technology for mobile services, more specifically for mobile payments. The objective of our paper is to evaluate in a systematic manner the potential of NFC as an upcoming technology for mobile payments. In order to ensure the rigor of our research, we used a formal and structured approach based on multi-actor multi-criteria methods. Our research provides one of the first assessment of NFC and a realistic picture of the current Swiss situation as we involved numerous mobile payment experts. Our findings show that Swiss industry experts are quite enthusiastic about the future of NFC.
\end{abstract}

\section{Introduction}

Mobile payments are defined as payments carried out with at least one mobile device. The market developments have been quite uneven throughout the world. Some countries are much more advanced in terms of technology deployed and business cases implementation.

In Japan, South Korea, and other Asian countries, several successful mobile payment solutions have already been launched (e.g., Mobile Suica, Edy, Moneta, Octopus). Mobile phones are used for making purchases at convenient stores, transit fares, and many other goods. Governments and influential mobile network operators (MNOs) pushed to enhance the development of mobile payment services, which could partially explain the greater success in Asia.

Latest numbers show that NTT DoCoMo is quite successful with the launch of the "osaifu-keitai" (mobile wallet function). In fact, in about one year, 20 million of their subscribers have been equipped with this feature and 1.5 million have already activated the credit card functionality [18]. There are 100,000 readers installed in Japan and this number is expected to be 150,000 at the end of March 2007.
In Europe and North America, the development of mobile payments has not been as successful, with the exception of several countries including Austria, Spain, Croatia, and the Scandinavian countries [25]. As an illustration, in Austria, Paybox is estimated to be used by over $150^{\prime} 000$ registered users and accepted by 4'000 merchants in March $2005^{1}$.

One major difference of the mobile payment services initiated in Asia, Europe, and the U.S. markets is the technology deployed. In fact, Japan and South Korea telcos distribute mobile phones ready for RFID technology (Radio Frequency Identification). This could be partially explained by the ubiquity of contactless cards (IC cards) for payment transactions. In Europe and the U.S., mobile payment systems are still mostly based on SMS (Short Message Service), USSD (Unstructured Supplementary Service Data), WAP (Wireless Application Protocol), or IVR (Interactive Voice Response). This was done in order to facilitate the uptake of mobile payments by using the existing technologies installed in the current customer base.

As these technologies were not making mobile payments very convenient and easy to use, companies are now testing new schemes based on NFC. To a certain extend, NFC is the fusion of a contactless smartcard (RFID) and a mobile phone. Mobile phone can therefore be used like a contactless card. NFC has a shorter range than other wireless technologies embedded in a phone (e.g., Bluetooth, Wifi). Another great feature of NFC is that mobile phones are capable to act as RFID tags or readers. This ability creates many opportunities for innovative services. There are several recurring examples used to illustrate the new possibilities offered by NFC.

One good example is the smart poster. An RFID tag is embedded in a poster. By waving the mobile phone close to the poster, the user get more information about the poster. Possible applications are ticketing or couponing. This could be seen as a new way to sell concert tickets through mobile phones.

The expected success of NFC is not only limited to the

\footnotetext{
${ }^{1}$ http://www.paybox.net/309.htm
} 
mobile payments capability. Many see that this technology will enable many innovative mobile services. Various applications in different industries (e.g., retail, logistics, transportation) could be developed to take advantage of the interaction between RFID tags and mobile phones. Access control scheme based on NFC also seems to be quite popular. This means that mobile phones could reinforce their position as a multi-function device. NFC also aims at facilitating communication between various devices (e.g., business card exchange, driver configuration), which could greatly contribute to the democratization of mobile computing.

As an illustration, at Atlanta's Philips Arena, Visa has been exploring the potential of NFC for the past years. Football fans were given a NFC mobile phone as an access device to enter the stadium and make payments for any purchase inside the stadium area. The results reported seem to be quite encouraging for further developments of $\mathrm{NFC}^{2}$.

By looking at the recent developments in Switzerland, we recognized that the market is still very immature despite the growing interest in mobile payments. Many companies from different industries are working on mobile payment projects and trials. However, the deployment of mobile payment systems is still very limited and touches only niche markets such as digital content, vending machines, and parking.

The structure of the Swiss market could be seen as an enabler or a disabler. An enabler because there are only few potential companies having interests in mobile payments. This could simplify the negotiation and discussions to synchronize efforts to bring a standard on the market. However, the clout of each stakeholder could be seen as a disabler. Swiss financial institutions have great influence due to their current active involvement in the payment sector and their well-known commercial ability to conduct profitable business cases. On the other side, mobile network operators have a privileged customer relationship with a large majority of the population. Swiss large retailers have a high volume of transaction and a great number of point of acceptance. In order to introduce a successful scheme on the market, there is a real need for collaboration between these economic giants. Logically, each of them have their own business priorities. Therefore, the coordination of these actors is not an easy task.

Based on a market survey, our results show that there is not any globally accepted mobile payment solution in the Swiss market. Nevertheless, there have been some trials running and some project developments in this field but nothing major for the consumers.

In a previous research, we compared different technology alternatives for mobile payments in the Swiss market. These prior studies $[15,16,17]$ have shown that card-based systems (e.g., smarcards, contactless cards) are still per-

\footnotetext{
${ }^{2}$ http://www.paymentsnews.com/2006/09/some_results_fr.html
}

forming quite well in the current market. Furthermore, the phone-based solutions compared in these analysis were not very well evaluated from an industry point of view. As a result, a technology disruption on the payment market was considered to be unlikely to occur with the current mobile phone technology (e.g., SMS). However, experts still expect NFC to be a technology enabler that could cause a disruption in the payment area. This motivated us to continue our study with the inclusion of the promising NFC.

Our research objective is to assess and evaluate the potential of NFC compared to other existing mobile payment technologies. In order to conduct a rigorous and relevant research, we used a formal and structured approach based on multi-actor multi-criteria methods and involved key Swiss experts. The research presented in this paper is an extension of a previous research comparing the existing payment technologies $[15,17]$. There are several differences in terms of the selected operational mode. However, the theoretical background used is identical.

The paper is organized as follows. In the next section, we review previous related work on mobile payment and technology foresight. Then, we present the previous research in order to clarify several methodological aspects and introduce the multi-actor multi-criteria approach. To explain the differences with the previous research, we describe the methodology used for the assessment of NFC. Further, we expose the results obtained. Finally, we provide a discussion and conclusions.

\section{Related Work}

In this section, we want to expose three different domains. First, we describe the mobile payment research that is related to our objective. Second, we explain the reason why we think that mobile payment and more particularly NFC could be considered as disruptive innovations. Third, we justify the reason why we use a multi-criteria (MCDM) technique for this technology foresight activity.

According to a recent literature review of mobile payment research done by Dahlberg et al. [7], most of the papers published covered technical issues (e.g., security, protocols, systems architectures) and consumer-centric study (e.g., adoption). This rather limited scope could be partly explained by the recent emergence of mobile payment research. We can expect to see more coming the next years as research in this domain is maturing.

Looking closer at mobile payment research, there are only very few papers evaluating the potential of NFC $[6,26,27]$. Moreover, the evaluation is very limited due to the descriptive approach of the research. Therefore, there is a real need to rigorously analyzed NFC using first hand data.

As we mentioned earlier, the consumer aspect has been 
well investigated. However, the other sides of the market (i.e., providers and merchants) seem to need more attention from the research community. Studying two-sided markets, such as electronic payment systems [9], from a stakeholders perspective is appropriate to get a better comprehension of the diffusion process [13]. In support of this view, Au and Kauffman studied the stakeholders side (including consumers, merchants and providers) using network externalities theory to study electronic billing adoption $[1,2]$.

In light of the many past mobile payment system failures, there is a real need to analyze and understand what requirements are needed to succeed on this market ruled by uncertainty. In fact, the technological trends are hard to predict as mobile technologies tend to behave as disruptive technologies [11].

Interestingly enough, mobile payments services are currently underperforming. They are already deployed in niche markets (i.e., digital content, ticketing, vending machines). The research and development investments will probably improve the current performance of the mobile phones as payment devices. We already see that some technologies (e.g., RFID, NFC) are bringing better performance (e.g., speed) than traditional payment cards. Therefore, an invasion of mobile payments in the payment market is not completely excluded. As mobile phones might first cohabit and then replace the cards, analyzing the current mobile payment market with the disruption theory seems appropriate.

Our literature review reveals that other research made a distinction for different types of disruptive innovations. More precisely, Markides discussed about radical product innovation that tends to be disruptive [12]. Based on his explanation, mobile payments could be also considered a radical product innovation, which is meant to be disruptive to both consumers and producers. Markides asserts that this type of innovation is more likely to be pushed by supply than demand [12]. Therefore, studying the supply-side of the market seems to be quite important to better understand the future developments of mobile payments.

Technology assessment and foresight are complex activities to study disruptive innovations. There are a relatively high number of parameters to consider in order to have a complete picture of the market. By definition, multi-criteria analysis is a very good candidate method to deal with this type of complex problem. MCDM methods imply a modeling activity, which should clarify many aspects, making the decision process more transparent. Moreover, Stewart considers MCDM to be largely concerned with the deployment of systematic methods to help address problems characterized by incomparable objectives, multiple stakeholders and conflicting interests [24].

Three distinct phases of the decision have been characterized by Simon [22]. These are intelligence, design, and choice. Bui argued that MCDM methods usually focus on the two last phases [4]. In our case, the objective is to use MCDM methods for the intelligence phase of the decision process. The idea is to examine the environmental conditions and unveil potential issues through the establishment of the decision. Following this idea, Salo et al. [21] have suggested the use of MCDM methods for technology foresight and concluded that there is potential "in terms of lending rigor and transparency to foresight process". Therefore, we adopted an MCDM approach for our research.

By looking at related work, we established a certain number of issues that need to be tackled and selected several theories to conduct our research. In summary, it seems that there is a lack of research studying the disruptive potential of mobile payment technologies using the supply-side point of view. Furthermore, MCDM methods seem to be good candidates for technology assessment and foresight activities.

\section{Previous Research}

In this section, we expose a previous research that was conducted to evaluate the current technologies in the Swiss payment market. We present this research to help the readers to understand our multi-actor multi-criteria approach, which was also used for the assessment of NFC.

As briefly explained before, we selected the use of a multi-actor multi-criteria to conduct our research. This approach involved a structure process that need to be done in order to build the first MCDM model. Salo et al. [21] proposed a process for the use of multi-criteria methods for technology foresight with the "multi-stakeholder" feature:

1. Identification of stakeholders

2. Development of goals, criteria, and alternatives

3. Model development

4. Score elicitation

5. Weight elicitation

6. Computation of overall performance measures

To build our models we primarily adopt the MCDM method ELECTRE I [3], initially designed for decisionmaking. In addition, we use a group decision extension proposed by Bui and Jarke [5] to search a consensus between all the experts. The objective was to capture the individual preferences of the experts and the potentially existing consensus between them. In our case, the rationale behind using an MCDM method was obviously not for decisionmaking but for technology assessment and foresight. The data collected to build the ELECTRE I models were compatible with another simple MCDM method, Weighted Sum Model (WSM) [10], which complements well the outcome of ELECTRE I by producing a ranking of the alternatives.

ELECTRE I belongs to the familly of the outranking methods. It basically compare different alternatives taking 
into account the advantages (i.e., concordance) and inconveniences (i.e., discordance) in the function of various criteria. The concordance index measures the degree of dominance of one action over another, based on the relative importance weightings of the decision criteria. The discordance index measures the degree to which an action is worse than another [20]. In summary, concordance and discordance indices can be viewed as measurements of satisfaction and dissatisfaction that a decision maker senses when choosing one action over another. Outranking relations are usually obtained with a combination of a high level of concordance and a low level of discordance.

The WSM method is quite simple. It computes a weighted sum of the evaluation for each alternatives. Therefore, each technology has a score, which naturally create a ranking of all the alternatives.

The complete description of all the algorithms used for this analysis and the following one can be found in [15].

Combining the two MCDM methods gives us two different perspectives on the data collected. ELECTRE I gives us outranking relations, which help us to compare two alternatives at a time. WSM gives us a global ranking of the technologies. Moreover, since the data collected are quite rich, we also explored them using some data cross-analysis techniques. To support our research, we designed a tool that was presented in [14]. This tool assists us for the data collection, computation, and visualization.

As stated above, to build a MCDM model, we need to establish alternatives and criteria. Table 1 comprises the alternatives we included in this analysis.

\section{Table 1. Technology Alternatives}

\begin{tabular}{|l|}
\hline Alternatives \\
\hline \hline Money \\
Regular cash (i.e. coins, bills) \\
Magnetic card \\
Plastic card with a magnetic stripe. \\
Smartcard \\
Plastic card with a chip \\
Contactless card \\
Plastic card equipped with an RFID chip \\
Mobile phone"remote" \\
Mobile phone using a remote network (e.g. GSM, GPRS, \\
UMTS). The payment transactions transit through a telco \\
mobile network infrastructure. This could be done using \\
SMS, Premium SMS, USSD, WAP. \\
Mobile phone "proximity" \\
Mobile phone using a proximity network (e.g. Bluetooth, \\
Infrared, RFID). The payment transactions transit through a \\
locally established wireless network. \\
\hline
\end{tabular}

We also pre-established a list of criteria extracted from the literature, discussed in focus groups and later validated with several experts. This was done to facilitate the work of the experts during the interviews. At this stage, each expert can still add or remove the criteria they considered relevant or irrelevant. This list will be naturally validated by the experts as they will select the criteria they perceive as relevant.

Ease of use. This criterion refers to "the degree to which a person believes that using a particular system would be free of effort" [8].

Cost. It regroups direct costs (e.g. cost of the technology, cost of implementation) and indirect costs (e.g. infrastructure operation and maintenance).

Reliability. The purchase process should be flawless as it involves a financial transaction.

User/Market Acceptance. This criterion represent the degree to which the user and the different stakeholders are already consenting to accept a technology for payments.

Security. Implicit security features (e.g. embedded encryption) and ease of securing the technology.

Flexibility. Degree to which the technology can be adapted in many different applications.

Value proposition improvement Improvement in value a technology could bring to the customer.

Maturity. Development state of the technology.

Speed. Implicit speed of the technology for payments.

Scalability. Ability to grow. Usability in small and large environment.

The weights of the criteria and evaluations done by the experts are collected during the evaluation phase.

To fully represent the Swiss mobile payment market, we focused on five industries (financial institutions, MNOs, retailers, public transportation companies, technology providers). By doing so, we improved the relevance of our study as well as the quality of our results. Table 2 depicts the name of the companies participating in the study. These companies are the major stakeholders in the Swiss market. The experts representing these companies are the decision-makers who will strongly influence the future of the payment market in Switzerland.

The MCDM methods require a large number of data and the time granted by the experts was somewhat short. Thus, we had to find a way to collect the data in a very easy process for the experts. We opted for the use of the "Pack of Cards" technique proposed by Simos [23] and later improved by Pictet and Bollinger [19]. The idea is to give to the experts cards with the name of each criterion inscribed. Then, we asked the expert to manipulate these cards, rank them, inserting blank cards to reinforce ranking differences. It appears that the active participation by the decision-markers in the procedure gives them an intuitive understanding of the approach[20].

After a few interviews, we realized that the manual card game was not the most effective method to collect data. Thus, we developed and integrated a computerized "Pack 
Table 2. List of the Companies Interviewed

\begin{tabular}{lllll}
\hline Financial institutions & Mobile telcos & Public transportation & Retailers & Technology providers \\
\hline Credit Suisse & Orange & SBB (Swiss Railways) & Coop & Crealogix \\
Corner Bank & Sunrise (TDC) & TL (Lausanne) & Migros & Jeronimo \\
Datatrans & Swisscom Mobile & ZVV (Zurich) & McDonalds & link-u \\
PostFinance & & & MyOne & Polyright (Kudelski) \\
Telekurs Multipay & & & & \\
UBS & & & & \\
Viseca/Aduno & & & \\
\hline
\end{tabular}

of Cards" technique. The data could be inserted automatically in our tool. Moreover, the results could be found in real-time which improved speed and interaction with the experts. More explanations about the use of this method can be found in [14].

Results showed that card technologies are preferred to phones for payment purposes. In general, the smartcard and contactless cards had a high ranking. The position of the smartcard can be confirmed by the shift from magnetic cards to more secure cards. Concerning the contactless card situation, it is more surprising as there are not any national payment schemes proposing contactless cards. This might be a weak signal that the market will slowly move toward the contactless cards scheme, especially with the support of the technology providers and the public transportation companies. This could also open an opportunity for NFC. However, the current phone-based solutions remain in last positions of most industry rankings. This could be explained as mobile phone-based payment schemes are still in a very early stage of development. There is still progress to be made in terms of ease of use, cost, reliability, and user / market acceptance. However, phone-based schemes already perform well in terms of flexibility and value proposition improvement. The three national mobile network operators consider value proposition improvement to be an important aspect, which explains why they believe that mobile phones have some future as a payment instrument.

This analysis was conducted using an asynchronous mode with the experts. In the next section, we present another possible approach, involving a face-to-face meeting with the experts.

\section{Methodology}

For the NFC assessment, we changed our operational mode. We adopted a real-time setting such as a roundtable. Our idea was to organize this roundtable with all the companies that participated in our research. The biggest challenge was to gather all the experts in the same room. We had to find a suitable date and a convenient location for everyone. Luckily, we were able to gather 16 experts representing 14 different companies. The roundtable occurred in October
2006. The representation of the industry was optimal as we covered all relevant industry sectors (Financial, Telecommunication, Retail, Technology, and Public transportation). A great majority of the experts participated in the previous campaign of interviews. Therefore, they were already quite familiar with our approach. Moreover, all the experts had knowledge about NFC, either because they are involved in national or international projects or they are closely monitoring the experiences made in the other countries.

We anticipated the roundtable would last two hours. The first part consisted of a presentation of the previous results (i.e., first MCDM model). The objective was to refresh memories and open a discussion. The presentation was based on a report distributed to the expert before starting the roundtable. We wanted the experts to have a common understanding of the results before the evaluation of NFC.

To evaluate NFC, we distributed individual forms for each expert. These forms were customized with the criteria previously selected by the expert during the evaluation of Disruption I. The experts had to evaluate NFC using the five value scale (i.e., weak, fair, average, good, excellent) as done before. We allocated about 15 minutes for this process. Then, we collected the form and started to manually input their evaluations in our tool. During that time, approximately 10 minutes, the experts were free to discuss with each other. After having inserted and computed the data, we immediately exposed the results to the experts.

As a reminder, we built two models for our research. The first one only contains the existing and most common payment technologies found (i.e., previous research). The aim of this first model was to assess the current situation in the Swiss market. The second model is based on the first model with the addition of NFC in the technology alternatives. This second model was used for the foresight activity as it involved an upcoming technology. In other words, we used the first model to establish the current preferences of the experts, and the second model to predict the potential success of NFC based on the experts' evaluations, in comparison with the existing technologies. 


\begin{tabular}{|c|c|c|c|c|c|c|c|}
\hline & Money & Magnetic & Smartcard & Contactless & Phone-Remote & Phone-Promixity & NFC \\
\hline Money & - & 21 & 7 & 7 & 0 & 0 & 0 \\
\hline Magnetic & 36 & - & 14 & 7 & 36 & 21 & 7 \\
\hline Smartcard & 36 & 79 & - & 21 & 43 & 50 & 21 \\
\hline Contactless & 7 & 21 & 29 & - & 36 & 50 & 14 \\
\hline Phone-Remote & 0 & 7 & 0 & 7 & - & 36 & 7 \\
\hline Phone-Promixity & 0 & 7 & 0 & 14 & 14 & - & 0 \\
\hline NFC & 14 & 14 & 14 & 14 & 64 & 71 & - \\
\hline
\end{tabular}

Figure 1. Outranking Relations of the Technologies Including NFC

\section{Results}

In Table 3, the ranking shows the potential of NFC to be a successful technology choice. This could be interpreted as a weak signal of a technology disruption in the payment market. Even though this ranking is an early evaluation, we can state a least that NFC performs much better than the other mobile phone-based technologies.

\section{Table 3. Technology Ranking Obtained with the WSM}

\begin{tabular}{l}
\hline Technology Ranking \\
\hline 1. Smartcard (3.8/5) \\
2. NFC (3.6/5) \\
2. Contactless Card (3.6/5) \\
4. Magnetic Card $(3.3 / 5)$ \\
4. Money (3.3/5) \\
6. Phone-Remote $(2.7 / 5)$ \\
6. Phone-Proximity $(2.7 / 5)$ \\
\hline
\end{tabular}

In terms of outranking relations (Figure 1), we can confirm the significant dominance of NFC over the PhoneRemote ( $64 \%$ of the experts had an outranking relation) and Phone-Proximity $(71 \%)$. Even the smartcard does not outrank the Phone-based alternatives as much (43\% and 50\%).

At this stage of the analysis, we cannot affirm that NFC will prevail. However, our results indicate that NFC is a real candidate for a disruption and should be taken into account in the payment market. Organizing this type of iteration with intervals of a few months would be useful to help follow the development of NFC.

Inserting an upcoming technology in the first MCDM model was quite successful. This demonstrated the flexibility of our multi-actor multi-criteria approach. Furthermore, the experts welcomed positively the results obtained.
It started a discussion about the future of NFC. The financial institutions and MNOs were very enthusiastic based on these results. On the other hand, the technology providers were more reserved as the development and implementation of NFC could bring many interoperability and compatibility issues. Overall, the industry seems to appreciate NFC and would like to see it on the market.

\section{Conclusions \& Discussion}

Our approach and results contributed to better assess the potential of NFC for payment purposes. NFC seems to perform quite well using the criteria that are relevant when taking a decision of selecting a technology. Our analysis also demonstrated that the Swiss industry anticipates NFC to be quite successful. As the industry experts are the architects for the next mobile payment solutions in Switzerland, this research unveiled new insights about the possible future of mobile payments and NFC.

The fact that NFC was well evaluated does not mean that mobile payments will take off in Switzerland. There are still many other problems to solve such as the value chain organization. Some experts doubt about the existence of a viable business case that would enhance the success of mobile payments. The Swiss market is still small in terms of the customer base. For a mobile payment system to succeed, there is a need for a high volume of transaction and a large customer base. If major industries do not sponsor mobile payments, there are almost no chance of success.

Even if the technology is deployed on the consumer side (e.g., NFC mobile phones), there will be issues on the side of the merchants. The current infrastructure of the merchants do not allow contactless payments in Switzerland. In Japan, many Edy and Suica (i.e., contactless card payment schemes) readers are installed. Embedding an RFID tag in the phone was just merging an existing and deployed technology with mobile phones. As explained, major retail- 
ers and public transportation companies should be involved. However, their current infrastructure cannot support mobile payments at the moment.

For further research, it could be relevant to study the business impacts of NFC. To further evaluate its potential, markets should be analyzed in terms of business case opportunities based on demography, regulation, market structure, and infrastructure readiness.

\section{Acknowledgement}

The work presented in this paper was supported by the National Competence Center in Research on Mobile Information and Communication Systems (NCCR MICS), a center supported by the Swiss National Science Foundation under grant number 5005-67322.

\section{References}

[1] Y. Au and R. Kauffman. Should we wait? network externalities, compatibility, and electronic billing adoption. Journal of Management Information Systems, 18(2):47-63, 2001.

[2] Y. Au and R. Kauffman. What do you know? rational expectations in information technology adoption and investment. Journal of Management Information Systems, 20(2):49-76, 2003.

[3] R. Benayoun, B. Roy, and B. Sussmann. Manuel de réference du programme electre. Note de synthese, formation n.25, Direction scientifique SEMA, Paris, 1966.

[4] T. Bui. Building effective multiple criteria decision models: A decision support system approach. Systems, Objectives, Solutions, 4:3-16, 1984.

[5] T. Bui and M. Jarke. A dss for cooperative multiple criteria group decision making. International Conference on Information Systems (ICIS), 1984.

[6] J. J. Chen and C. Adams. Short-range wireless technologies with mobile payments systems. The 6th International Conference on Electronic Commerce (ICEC), 2004.

[7] T. Dahlberg, N. Mallat, J. Ondrus, and A. Zmijewska. Past, present and future of mobile payments research - a literature review. Electronic Commerce Research and Applications, Forthcoming.

[8] F. D. Davis. Perceived usefulness, perceived ease of use, and user acceptance of information technology. MIS Quarterly, 13(3):319-340, September 1989.

[9] D. Evans and R. Schmalensee. Paying with plastic : the digital revolution in buying and borrowing. Cambridge, Mass.: MIT Press, 2nd edition, 2005.

[10] P. C. Fishburn. Additive utilities with incomplete product set: Applications to priorities and assigments. Operations Research Society of America (ORSA), Baltimore, MD, USA, 1967.

[11] J. Funk. Mobile Disruption: The Technologies and Applications Driving the Mobile Internet. John Wiley and Sons, New Jersey, 2004.
[12] C. Markides. Disruptive innovation: In need of better theory. Journal of Product Innovation Management, 23(19-25), 2006.

[13] S. Oh, H. Lee, S. Kurnia, R. Johnston, and B. Lim. A stakeholder perspective on successful electronic payment systems diffusion. The 39th Annual Hawaii International Conference on System Sciences (HICSS), 2006.

[14] J. Ondrus, J.-S. Monzani, and Y. Pigneur. A gdss for visualizing and assessing a technology environment. The 12th Americas Conference on Information Systems (AMCIS), 2006.

[15] J. Ondrus and Y. Pigneur. A multi-stakeholder multi-criteria assessment framework of mobile payments: An illustration with the swiss public transportation industry. The 39th Annual Hawaii International Conference on System Sciences (HICSS), 2006.

[16] J. Ondrus and Y. Pigneur. Towards a holistic analysis of mobile payments: A multiple perspectives approach. Electronic Commerce Research and Applications, 5(3):246-257, 2006.

[17] J. Ondrus and Y. Pigneur. Cross-industry preferences for mobile payments development in switzerland. Electronic Markets, 17(2), 2007.

[18] N. Parmelee. Docomo's holding strong. http://www.fool.com/investing/international/2007/02/ 01/docomos-holding-strong.aspx, February 1, 2007 (Last checked: February 6, 2007).

[19] J. Pictet and D. Bollinger. Adjuger un marché au mieuxdisant. analyse multicritère, pratique et droit des marchés publics. Presses polytechniques et universitaires romandes, Lausanne., 2003.

[20] M. Rogers, M. Bruen, and L.-Y. Maystre. ELECTRE and Decision Support: Methods and Applications in Engineering and Infrastructure Investment. Kluwer Academic Publishers, 2000.

[21] A. Salo, T. Gustafsson, and R. Ramanathan. Multicriteria methods for technology foresight. Journal of Forecasting, 22(2):235-255, 2003.

[22] H. A. Simon. A behavioral model of rational choice. Quarterly Journal of Economics, 6:99-118, 1955.

[23] J. Simos. Evaluer l'impact sur l'environnement. Presses polytechniques et universitaires romandes, 1990.

[24] T. Stewart. A critical survey of the status of multiple criteria decision making theory and practice. OMEGA, 20:569-586, 1992.

[25] K. Taga and J. Karlsson. Arthur D. Little Global M-Payment 2004. Technical report, Arthur D. Little's Telecommunications, IT, Media \& Electronics (TIME) Practice, Vienna, Austria, 2004.

[26] E. Valcourt, J.-M. Robert, and F. Beaulieu. Investigating mobile payment: supporting technologies, methods, and use. IEEE International Conference on Wireless And Mobile Computing, Networking And Communications (WiMob), 2005.

[27] A. Zmijewska. Evaluating wireless technologies in mobile payments - a customer centric approach. The Fourth International Conference on Mobile Business (ICMB'05), 2005. 